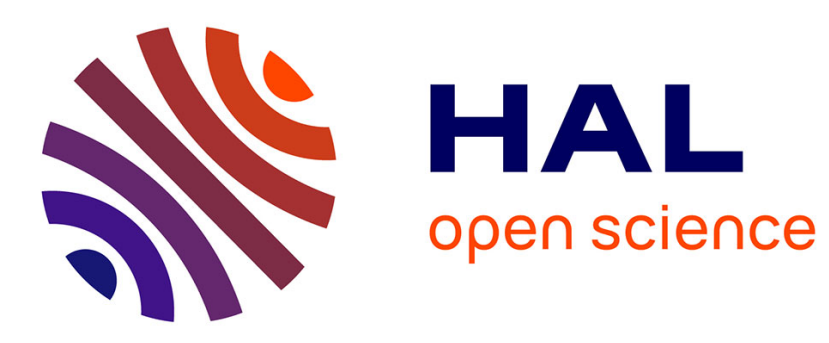

\title{
Modeling of Infrared Heating of Thermoplastic Sheet Used in Thermoforming Process
}

\author{
Fabrice Schmidt, Yannick Le Maoult, S Monteix
}

\section{To cite this version:}

Fabrice Schmidt, Yannick Le Maoult, S Monteix. Modeling of Infrared Heating of Thermoplastic Sheet Used in Thermoforming Process. International Conference on Advances in Materials And Processing Technologies (AMPT), Sep 2001, Leganes, Spain. 10.1016/S0924-0136(03)00291-7 . hal-02055829

\section{HAL Id: hal-02055829 https://imt-mines-albi.hal.science/hal-02055829}

Submitted on 4 Apr 2019

HAL is a multi-disciplinary open access archive for the deposit and dissemination of scientific research documents, whether they are published or not. The documents may come from teaching and research institutions in France or abroad, or from public or private research centers.
L'archive ouverte pluridisciplinaire HAL, est destinée au dépôt et à la diffusion de documents scientifiques de niveau recherche, publiés ou non, émanant des établissements d'enseignement et de recherche français ou étrangers, des laboratoires publics ou privés. 


\title{
MODELING OF INFRARED HEATING OF THERMOPLASTIC SHEET USED IN THERMOFORMING PROCESS
}

\author{
F.M. Schmidt*, Y. Le Maoult* and S. Monteix** \\ *Ecole des Mines d'Albi-Carmaux, Route de Teillet, 81013 ALBI CT Cedex 09 (France) \\ **Sanpellegrino (Nestlé Company), 35010 S. Giorgio in Bosco (PD) Via Valsugana 5 (Italy)
}

\begin{abstract}
Thermoforming consists of warming a plastic sheet and forming it into a cavity or over a tool using vacuum, air pressure and mechanical means. The process begins by heating a thermoplastic sheet slightly above the glass transition temperature, for amorphous polymers, or slightly below the melting point, for semi-crystalline materials. As the final thickness distribution of the part is drastically controlled by the initial temperature distribution inside the sheet, it is very important to optimise the heating stage. In most of the thermoforming machine, this step is performed using an infrared oven constituted of long waves infrared emitters. The goal of this study is to determine the efficiency of short waves infrared emitters (halogen lamps) for the heating step. The infrared heating of thermoplastic sheets will be modelled following two steps: an experimental set-up developed in our laboratory permits to measure the influence of parameters such as heaters temperature, incidence of the radiation, heat transfer coefficient ,.. An 880 LW AGEMA infrared camera is used to evaluate the surface distribution of the transmitted heat flux by measuring the temperature distribution on the surface of the thermoplastic sheet. In addition, a numerical model using control-volume method (software called PLASTIRAD) has been developed to simulate the heating stage. In particular, it takes into account the spectral properties of both heaters and plastic sheet as well as the heaters directivity. Comparisons between experimental data and numerical simulations allow validating the numerical model using different types of emitters and polystyrene (PS).
\end{abstract}

KEYWORDS: thermoforming process, polystyrene, halogen lamps, surface temperature measurement, infrared camera, control volume method

\section{INTRODUCTION}

In figure 1, the plug-assisted thermoforming process is sketched. The heating zone is constituted of upper and lower rows of infrared emitters, which are used to warm the plastic sheet prior to forming $[1,2]$.

Figure 1: Plug-assisted thermoforming process

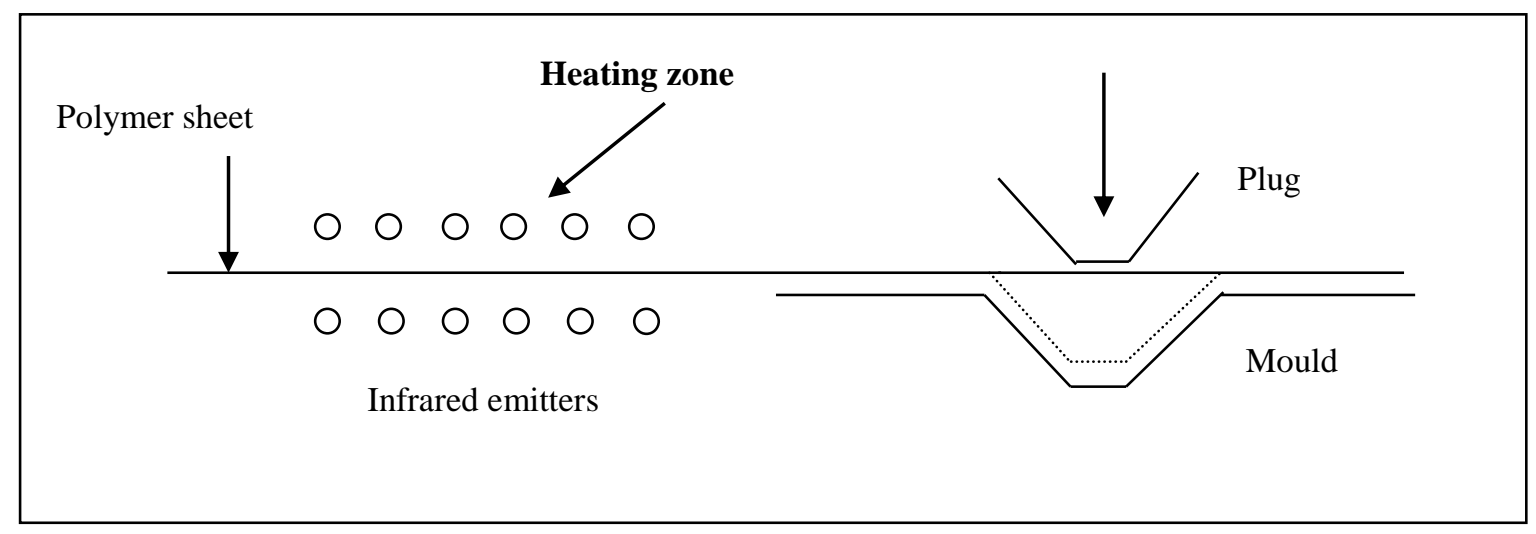


In most of the thermoforming machines, the heating step is performed using an infrared oven constituted of long waves infrared emitters (3-5 $\mu \mathrm{m}$ spectral bandwidth). The goal of this study is to determine the efficiency of short waves infrared emitters (halogen lamps) for the heating step (0.76$2 \mu \mathrm{m}$ spectral bandwidth) in the thermoforming process. For the purpose, a representative polymer of the thermoforming process has been chosen, i.e. the polystyrene (PS). According to Jammet [3], this polymer represents $49 \%$ of the entire thermoformed polymers. Then, comparisons will be made upon energetic criterion between three different emitters: long waves infrared emitters (ELSTEIN), average waves infrared emitters (TQS) and halogen lamps (PHILIPS).

\section{EXPERIMENTAL SET-UP}

Figure 2 shows the experimental set-up, which has been developed in order to measure the surface temperature evolution when a white PS sheet is heating using an infrared lamp (one or more if necessary). The polystyrene sheet is mounted in an isolating frame. The surface dimension of the sheet is $135 \mathrm{~mm} \times 100 \mathrm{~mm}$ and the thickness is $1.63 \mathrm{~mm}$. An $880 \mathrm{LW}$ AGEMA I.R. camera (8-12 $\mu \mathrm{m}$ bandwidth) is used to evaluate the surface distribution of the transmitted heat flux by measuring the temperature distribution on the back surface of the sheet The frequency of analysis is 25 frames/s and the device is connected to a 12 bit data acquisition board drive with a real time software. The experimental set-up allows for monitoring the transient surface temperature distribution. An aluminium polish sheet with an aperture (diaphragm) can be placed between the polystyrene sheet and the lamp in order to insure a constant view factor between the different lamps and the polymer sheet.

Figure 2: Experimental set-up overview

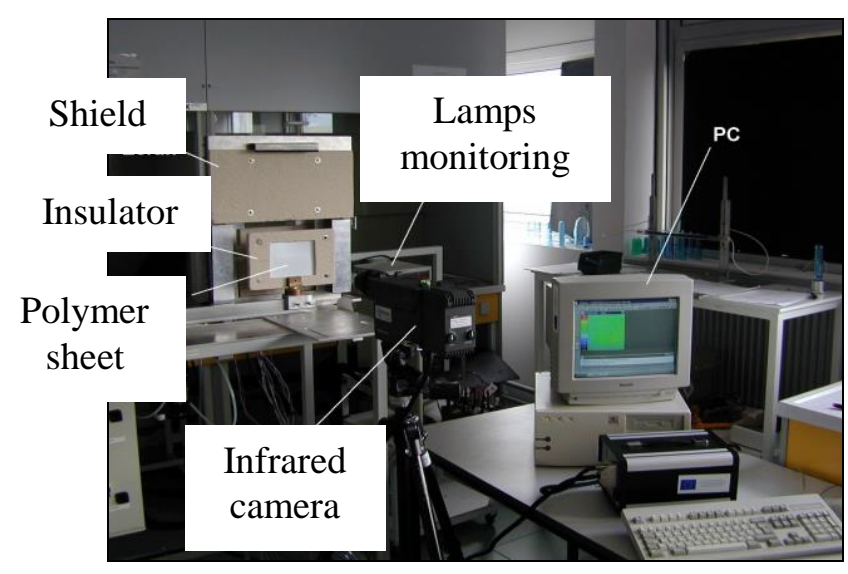

Side-view of the infrared oven

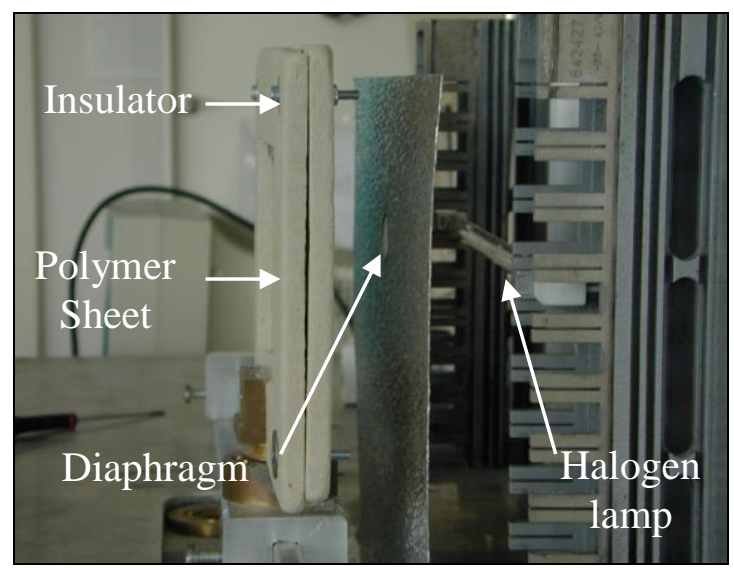

\subsection{Heat source characterisation}

The halogen lamps used in the infrared oven (PHILIPS 900W) are composed of a coiled tungsten filament (length: $300 \mathrm{~mm}$ ), contained in a quartz tubular enclosure (diameter: $10 \mathrm{~mm}$ ) filled with a neutral gas (Argon) and coated on its back with a ceramic reflector in order to increase the heat flux received by the product. This lamp as well as the ELSTEIN and the TQS lamps are presented in figure 3. Spectral properties of these elements have already been measured in previous works [4,5]. Using these data, the tungsten filament and quartz tube temperatures are calculated using a net radiation method [6]: 


$$
\begin{gathered}
P-\varepsilon_{F i l}\left(T_{F i l}\right) S_{F i l} \sigma T_{F i l}{ }^{4}-2 \pi L_{Q} k_{\text {Argon }}\left(T^{*}\right) \frac{T_{F i l}-T_{Q}}{d_{Q}}=0 \\
\ln \left(\frac{d^{2}}{d_{F i l}}\right) \\
\alpha_{Q}\left(T_{F i l}\right) \varepsilon_{F i l}\left(T_{F i l}\right) S_{F i l} \sigma T_{F i l}{ }^{4}+2 \pi L_{Q} k_{\text {Argon }}\left(T^{*}\right) \frac{T_{F i l}-T_{Q}}{\ln \left(\frac{d_{Q}}{d_{F i l}}\right)}-\varepsilon_{Q} S_{Q} \sigma T_{Q}{ }^{4}-h S_{Q}\left(T_{Q}-T_{\infty}\right)=0
\end{gathered}
$$

Where $\mathrm{P}$ is the electrical power of the lamps; the indices Fil and Q refer respectively to the filament and the quartz tube, $\mathrm{T}$ is the temperature, $\mathrm{L}$ is the length of the lamp, $\mathrm{d}$ the filament or the quartz tube diameter, $\varepsilon, \alpha$ the emissivity and absorptivity. $\mathrm{T}^{*}$ is assumed to be equal to $\frac{T_{F i l}+T_{Q}}{2}$. We have simplified this model by computing directly total parameters instead of spectral ones (as emissivity and absorptivity) with polynomial functions depending on temperatures which is easier and saves time. The temperatures of the filament and the quartz tube are computed at steady state using a Newton-Raphson method. The results of this computation are shown in figure 4. Additional curves are plotted on the same graph, they are related to experimental measurements: Colour temperature of the filament and temperature computed with a resistivity method. At the nominal power of $1 \mathrm{~kW}$, we have found the following values:

Table 1 - Filament and quartz temperatures

\begin{tabular}{|c|c|}
\hline $\begin{array}{c}\text { Filament temperature } \\
(\mathrm{K})\end{array}$ & $\begin{array}{c}\text { Quartz temperature } \\
(\mathrm{K})\end{array}$ \\
\hline 2360 & 730 \\
\hline
\end{tabular}

As shown in figure 4, the discrepancy between the extreme curves is high: greater than $100 \mathrm{~K}$ around $2350 \mathrm{~K}$. This fact is due to the lack of knowledge on the properties of this particular kind of tungsten (coiled filament). On the other hand, "colour" temperature remains difficult to measure at such level of power. In order to conclude, we have chosen the computed temperature as a "mean" temperature, lower and upper limits of the temperature, at $1 \mathrm{~kW}$, will be considered as the global uncertainty.

Figure 3: PHILIPS ( with and without reflector) ELSTEIN and TQS lamps
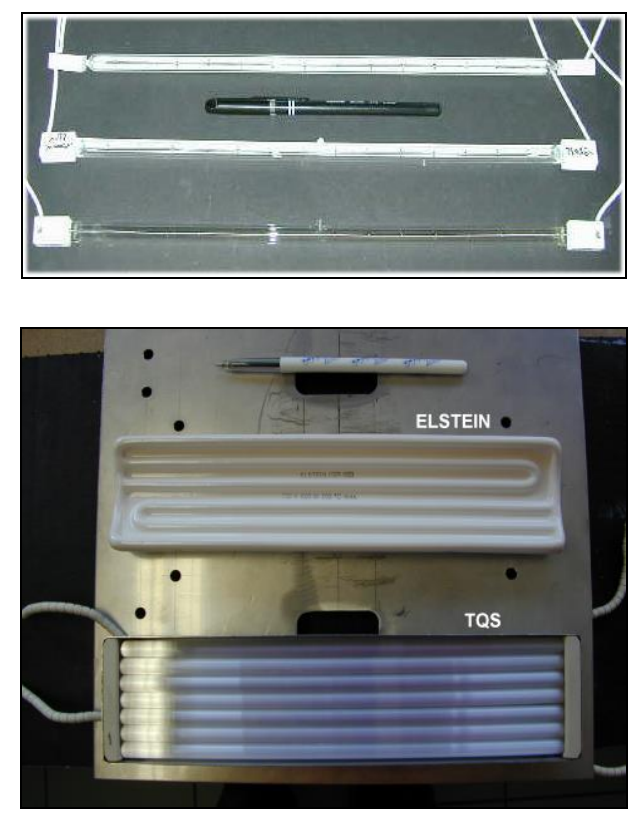
Figure 4: Filament temperature versus electrical power

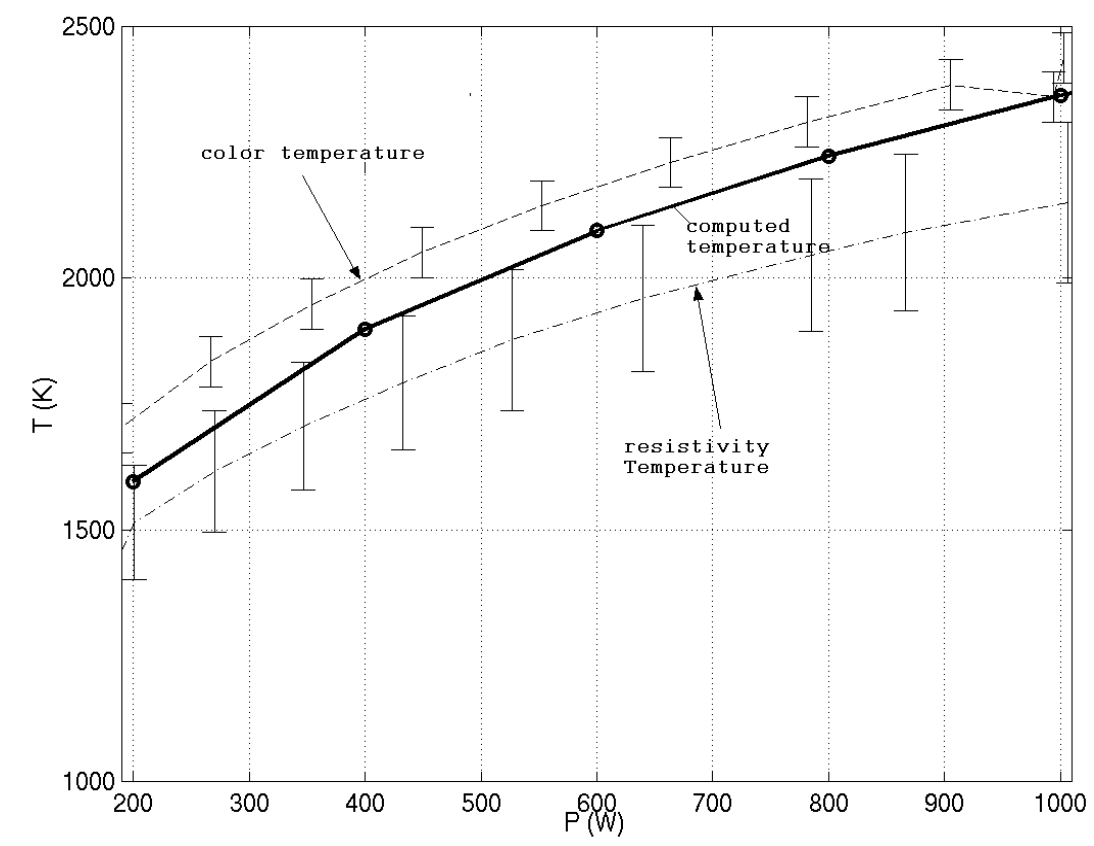

Using experimental set-up described in [4,5], the efficiency factor of the ceramic reflector has been measured:

$\mathrm{k}_{\mathrm{r}}\left(\theta, \mathrm{T}_{\mathrm{r}}\right)=\frac{\Phi_{r}\left(\theta, T_{r}\right)}{\Phi_{w}\left(\theta, T_{r}\right)}$

The index $r$ and $w$ refer respectively to the lamp with a ceramic reflector and without reflector. The angle $\theta$ covered by a detector around the heater and $T_{r}$ the temperature of the reflector. This value is obtained using a thermopile detector with a large spectral bandwidth $[0.25,26 \mu \mathrm{m}]$. The output signal delivered by the thermopile is related to the flux emitted by the lamp, so the ratio of the two fluxes measured by the detector and introduced in (2) gives the efficiency of the coating. We have checked that this efficiency is unaffected by the variation of the temperature of the filament and that the emission of the lamp is quasi isotropic. Therefore, we have obtained:

$\mathrm{k}_{\mathrm{r}}=1.36 \pm 0.02$

\subsection{PS spectral properties characterisation}

Spectra data will be used as a database in the numerical simulation (see section 3) as well as for the surface temperature distribution measurements. In the literature, we found few papers referring to Polystyrene spectral properties measurements [7,8]. 1.63-mm white PS sheets were processed by extrusion moulding. In addition, the previous thick sheets were polished in order to obtain samples of $0.07-\mathrm{mm}$ thickness, Then, we have proceeded to spectral properties measurements (transmitivity, reflectivity) using a Perkin-Elmer FT-IR spectrometer. We have found that the polymer is opaque for wavelengths in the range of 8 to $12 \mu \mathrm{m}$ with an integrated emissivity of 0.95 . This bandwidth corresponds to the one of the infrared camera. In figure 5, the PS absorbtivity $\alpha_{\lambda}$ is plotted versus wavelength both for the $1.63-\mathrm{mm}$ sheet (a) and the $0.07 \mathrm{~mm}$ thin film (b). 
Figure 5: Absorptivity versus wavelength

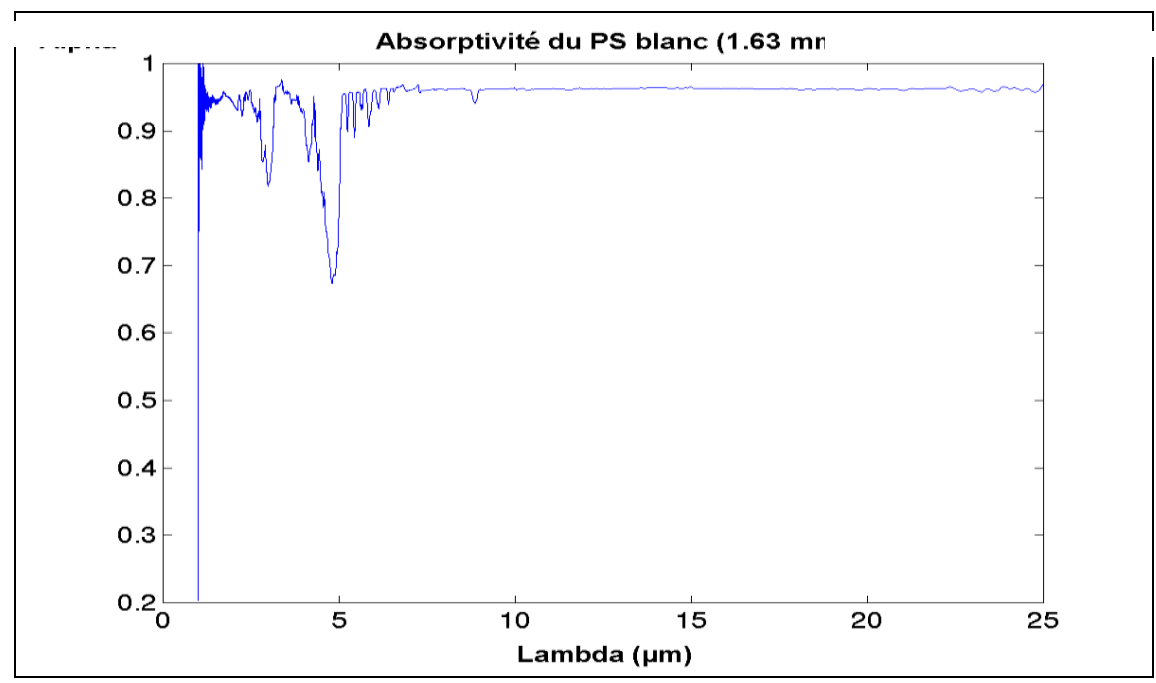

(a)

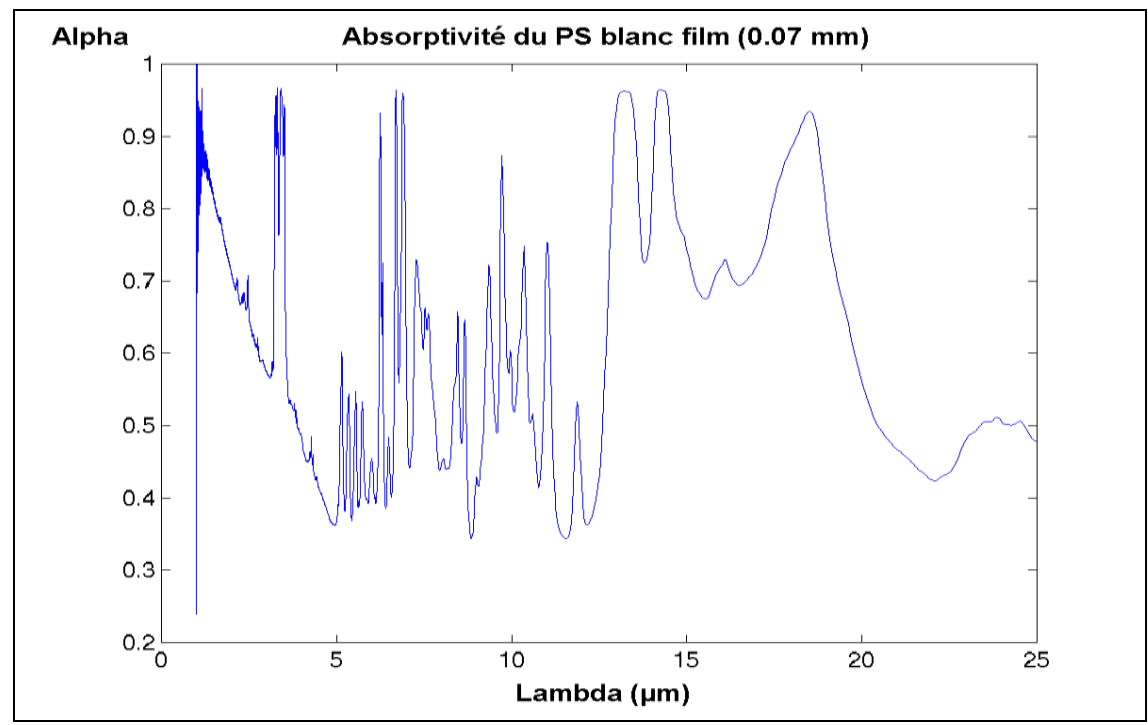

(b)

\section{NUMERICAL MODELING}

3D control-volume software, called PLASTIRAD, has been developed in order to compute heat transfer during the infrared-heating step. The sheet is meshed using cubic or hexahedral elements so-called control volumes [9]. The temperature balance equation including radiant heat transfer (thermal power absorbed by the semitransparent PS sheet and radiated from halogen lamps) is integrated over each control volume and over the time from $t$ to $t+\Delta t$ :

$$
\int_{\Delta t \Omega_{e}} \int_{\Omega_{e}} \rho c_{p} \frac{\partial T}{\partial t} d \Omega d t=-\int_{\Delta t \Gamma_{e}}\left(\overrightarrow{q_{c}} \cdot \vec{n}\right) d \Gamma d t+\int_{\Delta t \Gamma_{e}}\left(\overrightarrow{q_{r}} \cdot \vec{n}\right) d \Gamma d t
$$

Where $\Omega_{\mathrm{e}}$ is the control-volume, $\mathrm{q}_{\mathrm{c}}$ and $\mathrm{q}_{\mathrm{r}}$ are the Fourier's conductive and the radiated fluxes. The unknown temperatures are computed at the cell centres of the elements. The specific lamp geometry is also considered, taken into account from a view factor computation. In our model, we assume a constant filament temperature and then a uniform source temperature. Thus the amount of radiation, 
reaching each front elements of the irradiated sheet, is performed with the contour method using Stokes theorem [10]:

$$
F_{H \rightarrow p}=\frac{1}{2 \pi S_{H}} \oiint_{\Gamma_{H} \Gamma_{r_{p}}} \ln r \cdot d \vec{r}_{H} \cdot d \vec{r}_{r_{p}}
$$

Where the subscripts $\mathrm{H}$ refers to the heater and $\mathrm{p}$ to the sheet front element under consideration, $\mathrm{r}$ is the distance between two elemental linear elements, issued from meshing the entire heater boundary $\Gamma_{\mathrm{H}}$ and $\Gamma r_{\mathrm{p}}$ for each surface of control element's boundary reaching the irradiated sheet's face. This contour method integration was chosen between different numerical view factor methods (Monte Carlo or geometrical method). This method allows a good accuracy with a very low computational time. An efficient numerical method based on Gaussian quadrature has been applied in order to perform the contour integration. The computation of the amount of incident radiation, for each surface element, is given in equation 6:

$$
\Phi\left(r_{p}\right)=k_{r} F_{H \rightarrow r_{p}} \frac{S_{H}}{S_{r_{p}}} \int_{\Delta \lambda} \varepsilon_{\lambda}\left(T_{F i l}\right) \pi L_{\lambda}^{0}\left(T_{F i l}\right) d \lambda
$$

Where $\varepsilon_{\lambda}$ is the spectral tungsten emissivity, $\mathrm{T}_{\text {fil }}$ the filament temperature, $L_{\lambda}{ }^{0}$ the blackbody intensity, $\lambda$ a given wavelength between $[0.2,10] \mu \mathrm{m}$ and $\mathrm{k}_{\mathrm{r}}$ the efficiency factor of the ceramic reflector. In a first approximation, internal radiant heat transfer is assumed mono-dimensional across the sheet thickness. The PS bulk temperature $(\leq 450 \mathrm{~K})$ is very low in comparison to the source temperature $\left(\mathrm{T}_{\text {fil }}>2000 \mathrm{~K}\right)$. Therefore, the assumption of cold material is convenient. This leads to express the transmitted flux across the thickness of the material, for an homogenous and amorphous PS, using the Beer-Lambert's law, if the coordinate y describe the thickness, we have, in a simple way, for the flux:

$\Phi_{\lambda}(y)=\Phi_{\lambda}(y=0) e^{-k_{\lambda} y}$

Where $\mathrm{k}_{\mathrm{r}}$ is the spectral absorption coefficient of our material.

\section{DISCUSSION}

\subsection{Model assessment}

First of all, we proceed to a heating step of a white PS sheet during 70 seconds using one halogen lamp. The distance between the lamp and the sheet is $50 \mathrm{~mm}$. It is to be noted that in this case, the diaphragm is not taken into account. The dimensions of the sheet are the same as in section 2 . The sheet is meshed using 2250 linear cubic elements $(15 \times 15 \times 10)$. Figure 6 shows characteristic back surface temperature distribution obtained by numerical simulation (a) and by experimental measurement (b). We obtained a qualitative agreement. More interesting is the temperature variation along the width and the height of the sheet from a cross-point located on the centre of the sheet (see figure 6-a). The maximum relative error for the temperature distribution along width (figure 7-a) is $2.5 \%$. In this case, the agreement is fair. Moreover, the relative error in the case of the temperature distribution along height (figure 7-b) increases from $4 \%$ at the sheet centre up to $35 \%$ at the sheet border. This discrepancy is due to the mono-dimensional absorption assumption in our model (see section 3). 
Figure 6: Back surface temperature distribution

(a)

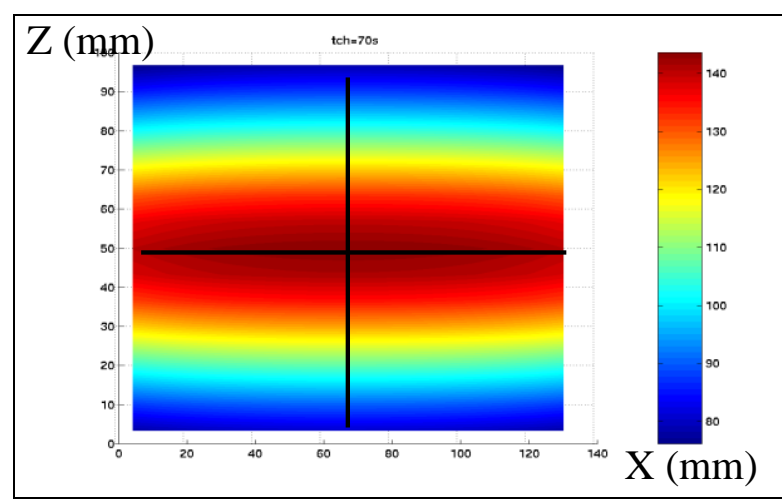

(b)

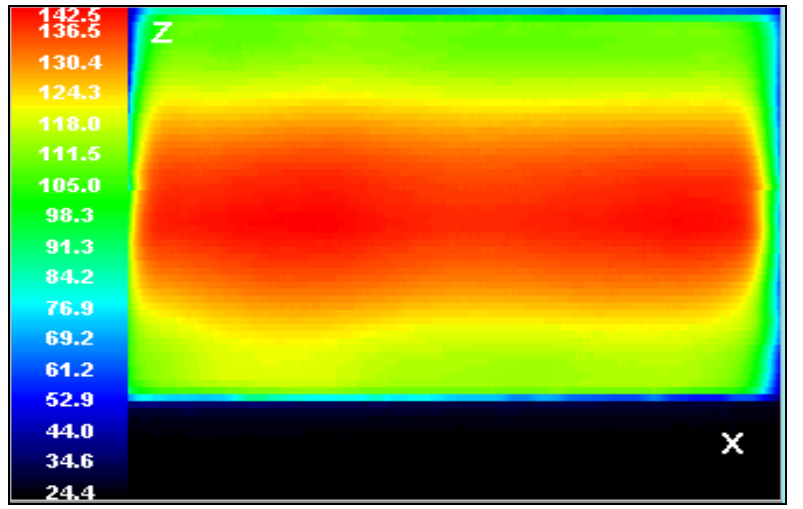

Figure 7: Numerical and experimental temperature distribution along width (a) and along height (b)

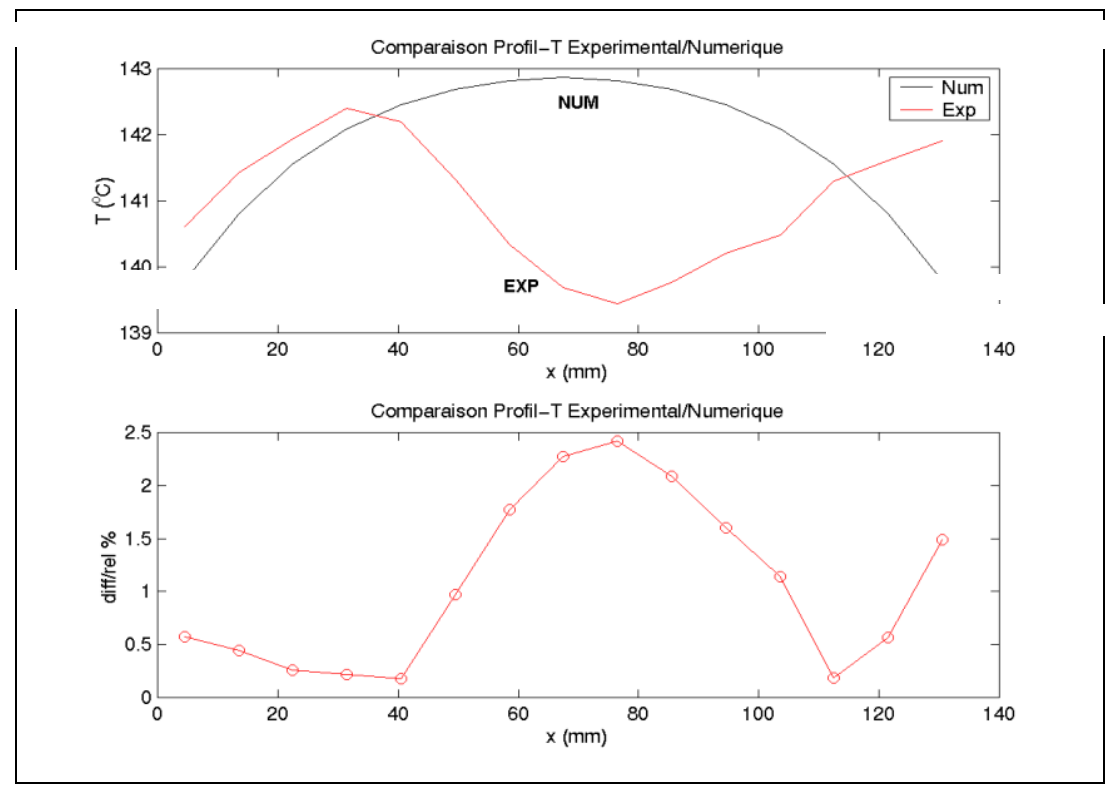

(a)

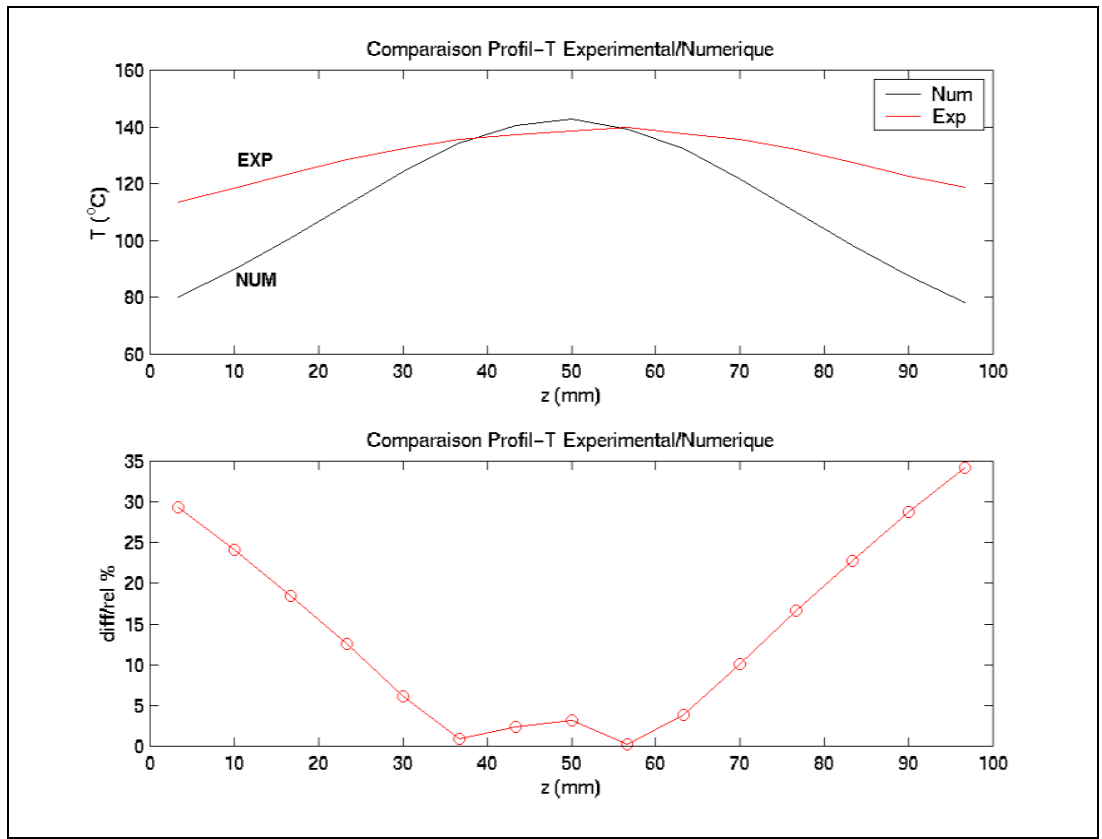

(b) 


\subsection{Comparison between different emitters}

In this sub-section, we compare three different emitters: a long wave infrared emitter (ELSTEIN 650W), an average wave infrared emitter (TQS 600W) and a halogen lamps (PHILIPS 900W) previously introduced in section 2 .

We proceed to a heating step of 290 seconds for each emitter using the experimental set-up described in section 2. This is the duration for the less efficient infrared emitter to achieve a maximum temperature of $74{ }^{\circ} \mathrm{C}$. The aluminium polish sheet with an aperture (diaphragm) is placed between the polystyrene sheet and the lamp in order to avoid geometric effect. Then, the temperature evolution is recorded versus time at the sheet centre using the infrared camera (see figure 8). Then, we calculate a simple energetic criterion :

$E_{L}=P_{L} \times t_{L}$

Where $E_{L}$ is the approximated energy consumed by each lamp, $t_{L}$ is the time required for each lamp to achieve the less efficient infrared emitter maximum temperature, $P_{L}$ is the electrical power of each lamp. If we applied the equation (8) to the curves of figure 8-a, we obtain the values refereed in table 2 .

Figure 8: Recorded temperature versus time at the sheet centre

(a)

$\mathbf{T}\left({ }^{\circ} \mathbf{C}\right)$

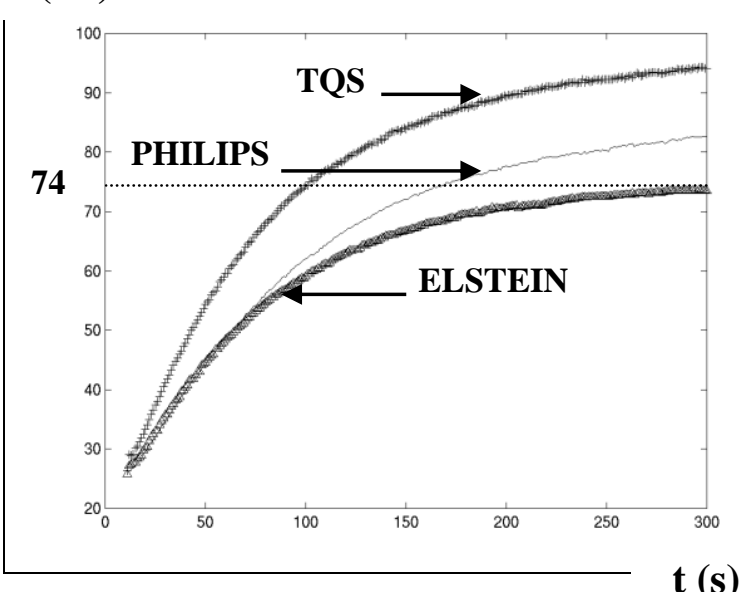

(b)

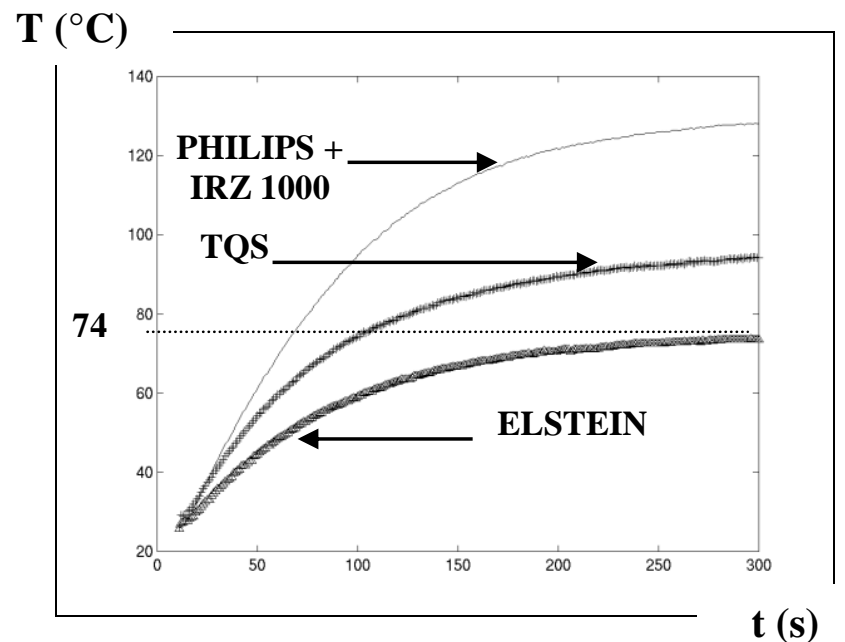

Table 2 -Energy consumed by each lamp

\begin{tabular}{|c|c|c|c|}
\cline { 2 - 4 } \multicolumn{1}{c|}{} & TQS & PHILIPS & ELSTEIN \\
\hline$E_{L}(\mathrm{~kW})$ & 54 & 144 & 188.5 \\
\hline
\end{tabular}

According to the criterion (equation 8), the energy efficiency of the halogen lamp is better than the long waves infrared emitters (i.e. ELSTEIN lamp). In addition, the PHILIPS lamp efficiency should be improved in comparison to that of the TQS lamp. For that, an aluminium reflector (IRZ 1000) has been placed in the back of the halogen lamp in order to increase radiant heat flux. In figure 8-b, the temperature evolutions of the different lamps are plotted versus time. Again, we calculate the energy consumed by each lamp (table 3 ).

Table 3 -Energy consumed by each lamp

\begin{tabular}{|c|c|c|c|}
\cline { 2 - 4 } \multicolumn{1}{c|}{} & TQS & PHILIPS & ELSTEIN \\
\hline$E_{L}(\mathrm{~kW})$ & 54 & 49.5 & 188.5 \\
\hline
\end{tabular}


Due to the presence of the aluminium reflector, the halogen lamp has now the best energy efficiency (i.e. lower energy consumed).

\section{CONCLUSION}

An experimental set-up has been developed in order to measure the back surface temperature distribution of a polystyrene sheet using an infrared camera and has permitted to compare the energy efficiency of three different emitters (TQS, ELSTEIN, PHILIPS). The comparisons, based upon a simple energetic criterion, allow demonstrating that the halogen lamp has the best energy efficiency. These preliminary results will be further improved and extended to other polymers, and particularly to Polypropylene (PP).

A 3D numerical model using control volume method has been developed to simulate the heating stage and then validated by comparisons with experimental data. This numerical model has to be improved in order to take into account the transmitted flux across the thickness without geometric assumptions (i.e. Beer-Lambert mono-dimensional law). 


\section{ACKNOWLEDGEMENTS}

PHILIPS LIGHTING and EDF-RENARDIERE Companies support this work. Special thanks go to R. Anbari for his help on the experiments.

\section{REFERENCES}

1. Adolf Illig, Pratique du thermoformage, (in french), Ed. HERMES Science Publications, Paris, p.151-184 (1999)

2. James L. Throne, Two-day seminar on thermoforming process and design, Basel (Switzerland), Technomic publisging AG (1998)

3. Jammet Jean-Claude, "Thermoformage", Techniques de l'ingénieur (in French), Vol. AM3, AM3660 (1997).

4. Monteix S., Schmidt F., Le Maoult Y. "Experimental study and Numerical Simulation of Sheet and Tubular preform Infrared Heating", QIRT 2000, Eurotherm Seminar N $64-R e i m s-F r a n c e$ (2000).

5. Monteix S., Schmidt F., Le Maoult Y., G. Denis and M. Vigny "Recent issues in preform radiative heating modelling", PPS 2001, Montreal (2001).

6. Petterson M., "Heat Transfer and Energy Efficiency in Infrared Papers Dryers", Ph. D. Thesis, Lund University, Sweden (1999).

7. K. Esser, E. Haberstroh, U. Hüsgen and D. Weinand "Infrared Radiation in the Processing of Plastics: Precise Adjustment-the Key to Productivity", Advanced in Polymer Technology, Vol. 7, p. 89-128 (1987)

8. T. Miyanaga and Y. Nakano "Analysis of Infrared Radiation Heating of Plastics", Central Research Institute of Electric Power Industry Tokyo, Japon (1990).

9. Patankar S.V., "Numerical Heat Transfer and Fluid Flow “, Ed. Mc Graw Hill, New-York (1980)

10. Rammohan R., “ Efficient Evaluation of Diffuse View Factors For Radiation”, Int. Journal. Heat and Mass Transfer, Vol 39,Nº p.1281-1286 (1996) 